\title{
Rhythmic Gymnastics vs. Boxing: Gender Stereotypes From the Two Poles of Female Sport
}

Authors' contribution:

\section{A) conception and design} of the study

B) acquisition of data

C) analysis and interpretation of data

D) manuscript preparation

E) obtaining funding

\author{
Piroska Béki ${ }^{\text {A-E }}$, Andrea Gál ${ }^{\text {A-E }}$ \\ Semmelweis University, Hungary
}

ABSTRACT

In recent decades, women have begun to take up types of physical activity traditionally considered masculine. They appeared in previously one-gender team sports such as football or water polo, and nowadays they are also involved in ice hockey, canoeing, and are active in numerous combat sports as well. On the other hand, men have entered sport fields previously only available to women, such as rhythmic gymnastics. By this, sport can be regarded not only as a scene of gender stereotyping, but also a scene of redefining the concepts of masculinity-femininity in the negotiating of gender relations. Owing to these phenomena, there has been an emergence of studies analyzing sports from a gender aspect as well as the generalizations related to athletes involved in these sports. These studies have primarily focused on the constructions of gender identities and gender roles of women participating in traditionally masculine sports (football, weightlifting, and bodybuilding).

This paper presents the results of empirical research designed to explore the opinions of top athletes involved in sports considered to be the most masculine and most feminine by the public and by sport experts: rhythmic gymnastics and boxing. They discussed their own sport and each other's sport. With the information obtained from the structured interviews $(n=22)$, it became possible to compare their social background, sport socialization and sport selection, as well as their conceptions of gender roles, femininity, and masculinity. As a conclusion of the research, it can be stated that from the aspects examined differences could mostly be observed in the circumstances of sport selection, but representatives of the two sports also diverged remarkably in their judgments about each other's sport. While female boxers did not voice extreme opinions about rhythmic gymnastics, representatives of the sport regarded to be the most feminine reflected on boxing in a stereotypical and prejudiced way, even given their lack of experience.

KEYWORDS

\section{Introduction}

Although female sport has undergone enormous development in the $20^{\text {th }}$ century, the emergence of the "weaker sex" has started in sports in which, due to their nature, could be regarded as the bastions of 
masculinity (football, ice hockey, water polo, and some track and field events such as pole vault and triple jump), but lags behind the situation that can be observed in androgynous sports. This can be explained by the fact that due to factors such as weaker physical condition, less stable psychological state and issues with controlling emotions, certain sports were only accepted for a long time as suitable for women. On the other hand, their participation in sports that could be characterized by a serious physical workload, physical contact, and a high level of aggression and tension, and therefore cannot be reconciled with the traditional social conception of femininity (Davisse \& Louveau, 1998) was rejected not only by men but by the women themselves. In the case of combat sports, for example, similar to the aforementioned sports, it is not only doubted by many, whether women have the physical ability needed for combat sports, and whether they can compete at a high standard and in a spectacular way. Yet it is also questioned whether the potential physical contacts and the high level of aggression could seriously threaten the physical health of the participants. This is why the question is often asked: Are such sports suitable for women? This is especially true for boxing, which is seen by the public as one of the most dangerous sports, which could even result in long-term injury. Although the International Boxing Association declared boxing to be unisex as early as in 1994, thereby opening the road to better professional and social recognition for the female branch, it was only in 2012 that the best female boxers could compete in three weight categories at the London Olympics.

The group of sports which were most accepted as suitable for women comprised the ones where during contest participants could preserve their femininity; what is more, with their aesthetic appearance and movement they can even emphasize it. Such sports are, for example, artistic gymnastics, figure skating, synchronized swimming, and perhaps most of all, rhythmic gymnastics. This female sport, which involves individual and group choreographies with or without hand equipment is indeed one of the most spectacular sports, and its representatives truly personify femininity. RG was introduced at the 1984 Olympic Games as an individual event, although it had been present under the event "portable apparatus" in the 1950s, and then in 1996 the all-round group competition was also included in the program. Nevertheless, even among sport lovers it is less known that in some countries, such as Spain, France, and Japan, rhythmic gymnastics is also done by males, and competitions are organized on a regular basis. This is probably due to the fact that modern rhythmic gymnastics, unlike its original form, includes show-type performances with more and more acrobatic elements, which, just as with aerobics provide the opportunity to make use of strength and skill, and thus can be attractive for men as well. However, by this, males enter a territory that used to be regarded as "exclusively feminine". Although men's RG is not yet present at the Olympics, world championships have been organized since 2003 .

So, just like other areas of social life (labor market, leisure activities, etc.), sport can also be characterized by the blurring of the borders between traditionally female and male areas, that is, sports are becoming androgynous. Even so, can gender stereotypes related to sports and athletes change during the process?

The main objective of the present paper is to explore the gender stereotypes related to the representatives of boxing and rhythmic gymnastics through their opinions about their own sport and each other's sport.

During the research, we tried to find answers to the following questions:

- Are there differences between their early sport socialization process and their sport selection?

- What differences can be discovered in the processes of gender socialization?

- Do the female representatives of the two sports diverge from the traditional female roles?

- How do the female athletes judge their own sport and the other's sport, and how do they see the representatives of the other sport?

During the analysis of the results, every aspect was examined, and it was considered feminine when the interviewee reported on traditionally female forms of behavior (activities characteristic of girls/women, feminine clothing, and dominance in housework). 


\section{Sport and gender}

The content of gender, that is, the social aspects of the two sexes, is constructed by society, and by ourselves, as we negotiate the concepts of masculinity and femininity and define the range of acceptable behavior. As written by Hadas (2003), the manifestations of masculinity and femininity are not universal or unchanged, but are historically and culturally defined, and their research is therefore certainly reasonable in present day civilizations. The $20^{\text {th }}$ century development of female sport was not only about the fact that instead of the passive spectator's role that was assigned to women in previous times, an increasing number of them became involved in sport as active participants, but also about the fact that in the past decades women have started to engage in forms of physical activity which were regarded as masculine. Parallel to this, sports that were considered as especially feminine raised the interest of men as well, such as aerobic or rhythmic gymnastics. This way, sport did not only remain the scene of gender stereotyping, but also that of redefining the concepts of masculinity and femininity, since women doing masculine sports and men engaged in feminine sports fall out of the gender categories which used to be regarded as binary, and in fact shift between the two poles. Gender-based research works, which have become popular in recent decades, were primarily woman-centered; however, by now they have become increasingly complemented by the issue of masculinity in the case of men involved in feminine sports.

The cultural differences between masculinity and femininity have become apparent for half a century in the gender-based categorization of sports. Based on the theory of Metheny (1965), women can choose from three groups of sports falling into different categories in terms of their social acceptance. The two endpoles constitute the masculine sports not recommended for women and the sports recognised as explicitly feminine. In the first group we can find the forms of physical activity during which there is physical contact with the opponent, heavy equipment is used, or the body is exposed to long-term workload. In the third group, that is, at the other end-point, there are sports done by light equipment, where opponents are separated by physical burden, and which can be characterized by fluidity, quickness, or aesthetic beauty. The rest of the sports belong to the middle category.

According to Postow (1980), the sport characteristics described by Metheny can be assigned to masculine features such as aggression, efficiency, and strength. Therefore, the sports in which these are needed are automatically labeled as masculine. However, the sports in which aggression is not only an advantage, but also a 'compulsory' element of the game (ice hockey, American football, etc.), are considered as especially masculine. In addition to these, it is those sports that are strongly connected to masculinity which contribute to the strengthening of male identity and its social recognition, for which again the example of American football is given by Postow.

\section{Women in men's sport}

The questions related to the performance of women become more articulated in the case of sports regarded as the "most masculine", such as boxing, weightlifting, bodybuilding, and wrestling. The normative ideas in connection with female body and feminine behavior become the most confused in these sports (Scraton et al., 1999). As it is noted by Halbert (1997) and McCaughey (1997), female boxers especially question the binary formula set up by Messner (1996), thus referring to gender and sexual identity which can be described as: sport = masculinity = heterosexuality and sport $?=$ femininity $?=$ heterosexuality? This is so, because in the ring female boxers show traits that are traditionally most identified with masculinity, such as aggression, strength, and high-level concentration. A good example of the still very much ambivalent attitudes to this sport is that some people see the performance of female boxers as serious sporting achievement, while others, as Pirinen (1997), quote the words of a correspondent at the 1994 Finnish championship, who called it peaceful dancing or disco dancing.

The other reason for the ambivalent judgment can be precisely the often-contradictory manifestations of the gender identity of women participating in traditionally masculine sports. As it has been mentioned above, in the boxing ring, women behave in a masculine way, or, according to some, as a weaker copy of 
men, but by willing to verify their femininity they strive to show the characteristics of the "weaker sex" in their clothing, make-up, and during social interactions. Who could be a more appropriate example of this than the female bodybuilder, who steps on front of the audience with muscles that would be appreciated by men, but in a glittering swimsuit, with long hair and make-up, and out of the competitions wears clothes that emphasize femininity?

When seeing ladies engaging in manly contests, few people would assume that some women are keen on boxing, because, regardless of their sexual orientation, they simply like violence and enjoy fighting, but cannot engage in this in their everyday lives. In a study on Danish female football, ice hockey and basketball players by Thing (2001), interviewees did not only report on that in these sports they get the space and chance to be aggressive, but also that they have to behave like that, otherwise they will have to leave the game as losers. In a study dealing with female wrestlers, Walton (2005) emphasized that wrestling does not only give an opportunity to learn a kind of sporting activity, but it symbolizes masculinity itself as well, therefore the women appearing in the sport can be regarded as 'unnatural.'

Gender stereotypes related to different sports have been investigated by sport sociologists and sport psychologists in western countries for decades. Matteo (1986) examined the extent to which an individual's overall experience with and personal commitment to athletic activities is constrained by the sex appropriateness of the sport, the sex of the individual, and the individual's classification on the Bem Sex Role Inventory ${ }^{1}$. No sex differences were found for levels of participation for either measure of participation. For both measures, neutral sports were preferred, followed by sex-appropriate and then sex-inappropriate sports. Females' experience and commitment was greater than that of males to feminine activities, whereas males' was greater than females' for masculine activities. Sex-typed males reported significantly less experience with and commitment to feminine sports than androgynous and undifferentiated males. When sex-typed females were compared with androgynous and cross-sex-typed females, they reported significantly less commitment to masculine sports. In her research, Koivula (1995) proceeded from the starting point that gender-based schematic processing has been shown to affect attitudes and behavior; there might be differences in the categorization of sports as masculine or feminine, between sex-typed and non-sex-typed individuals. The findings his study showed differences in gender appropriateness ratings between groups classified according to the Bem Sex Role Inventory, and also between men and women. Men, in general, and sex-typed men, in particular, were more inclined to stereotype sports as masculine or feminine. An explanation might be that these individuals engage to a greater extent in gender-based schematic processing. A possible additional explanation could be that childhood socialization into sports may serve as a means of providing proof of boys' manliness and the validation of prejudices against women, and that the need for this proof is stronger among sex-typed men.

Research works dealing with the sport selection and the gender identity of women participating in sports that are considered to be masculine attempt to discover what kind of childhood socialization influences contributed to the orientation towards boxing, football, handball etc. on the one hand, and on the other hand, these studies focus on investigating how much this sport selection has been accompanied by forms of behavior that are characteristic of boys rather than girls.

When examining female footballers, Scraton et al. (1999) experienced that all of their interviewees (German, Danish, Spanish, and English football players) were "tomboys". In their childhood, they perceived this as positive, as being more mobile, they found boys' games more exciting and football was of course one of these. In a study about female boxers, Mennesson (2000) reported similar results: the majority of these women recalled that in their childhood they used to wear boyish clothes, behave like boys and play boyish games. In both papers it can be read that for these female athletes their father, and in several cases, their

\footnotetext{
${ }^{1}$ The Bem Sex-Role Inventory (BSRI) was created and published by Sandra Bem in 1974. It is a measurement of masculinity-femininity and gender role perceptions. It assesses how people identify themselves psychologically. Bem's goal of the BSRI was to examine psychological androgyny and provide empirical evidence to show the advantage of a shared masculine and feminine personality versus a sex-typed categorization (Retrieved 09.23. 2012 from http://www.wikipedia.org).
} 
brother was an important role model, or a peer-group consisting of mostly boys was an important reference group. These models found the boyish behavior of the girls favorable from the aspect of sport, in many cases contrary to the female members of the family, especially the mother. It is worth noting here that this contradicts the previous observations according to which in the process of sport socialization in the case of boys the influence of the father is stronger, whereas with girls it is the mother who more strongly affects their involvement in sport (Snyder \& Spreitzer, 1973; Watson, 1975).

The boxers and footballers that were the subjects of these research works started to engage in sport at the age of 6-7 years. As it is written by Hasbrook (1993), physical activity can be an important part of gender differentiation; however, it plays a fundamentally important role in the formation of boys' gender identity and body image. In the case of female football players and boxers, these patterns diverged from the traditional ones, and not only sporting activity itself, but also the support of sporting habitus also started at a very early life stage. The boyish behavior, the identification with men's roles, the perception of 'girlish' activities as boring and their rejection led to an identity model which can be described as masculine rather than feminine. This did not cause a problem for female athletes until adolescence, when it is mostly the visible patterns of gender behavior that are modified, primarily owing to the influence of the peer-groups and the media. In this age group, gender roles and the stereotypes related to them exert a greater influence on the decisions and activities of youngsters. According to Hasbrook, sport plays a more important role for boys in this period as well, mainly in the formation of a strong, masculine physical appearance, and as a terrain of demonstrating competitiveness, endurance, and effectiveness. From the reminiscences of female athletes engaged in different kinds of boxing asked by Mennesson (2000), the previous experience was reinforced, according to which it is not easy to move forward from a boyish childhood to adolescence and beyond when proving femininity is 'compulsory'; this is especially difficult inside the ring, mainly in the full-contact versions of the sport. Whether or not they succeed is decided by the feedback from their environment, primarily the male coaches and training partners, the spectators, and, of course, the media.

\section{$R G$ : not a female preserve anymore?}

There are fewer exclusively feminine sports than traditionally masculine sports, since concerning its traditions sport itself is masculine. This is why much fewer men appear in these sports than women do in the ones that are regarded to be masculine. We labeled sports that are aesthetically beautiful, require feminine movement, and avoid physical contact as explicitly feminine. This included synchronized swimming, RG, dancing, and figure skating. Men have always participated in the latter two sports, but the set of movements still make it feminine. As Kemberidou et al. (2009) summarized in their study, the medical and social discourses of the $19^{\text {th }}$ and early $20^{\text {th }}$ centuries on female physicality and identity (Sandow, 1898; Webster, 1930; Pfister, 1990; Guttmann, 1991) established stereotypes concerning performance and capabilities (Kirk, 2002; Hills, 2006; Kamberidou, 2007). Later at the beginning of the $20^{\text {th }}$ century, when women started to engage in competitive sport, it was no different; only women competing in feminine sports were accepted by the society. Such was rhythmic gymnastics, which used to be acknowledged as the sport most appropriate for expressing femininity, but in the last two decades has lost its exclusivity and is opening up for men as well. Consequently, the question can be raised in connection with this sport: whether the sport will become more masculine, or its male representatives will be expected to demonstrate feminine qualities, which might lead to the feminization of male rhythmic gymnasts. While the research dealing with female weightlifters, boxers, and ice hockey players has focused on the question how much the representatives of these sports can preserve their femininity, experts studying rhythmic gymnasts investigate whether the males engaging in the sport can preserve their masculinity. In their paper, Chimot and Louveau (2010) examined how young male rhythmic gymnasts construct their masculine identity, as their sport shows contradictory traits to the traditional ones in this respect. This ambivalence generates tension between social expectations and the sport selection of the athlete, which has to be somehow managed by the athletes (abandoning the sport, accepting stigmatization or being different). After investigating the identity and equal opportunities of male rhythmic gymnasts, Kemberidou et al. (2009) reached the conclusion that, as the sport became unisex, it was 
contributing to the breakdown of gender barriers which had been previously observed. This is best symbolized by the fact that, in addition to the previously existing individual and group performances, mixed couples can also perform.

\section{Hypotheses}

Before starting the investigation it was assumed that

- sport selection is determined by childhood role behavior, which was boyish in the case of female boxers, whereas with rhythmic gymnasts it showed more feminine characteristics,

- in the case of women engaging in traditionally masculine sports, there is a close relationship between gender socialization and sport socialization,

- women competing in rg insist on maintaining their traditional female roles more strongly than their boxing counterparts,

- the athletes link different personality traits to the representatives of their own sport and to competitors of the other sport.

\section{Methods}

Our research was carried out with the help of qualitative methods. We conducted in-depth interviews based on a predefined set of elements with representatives of female boxing and rhythmic gymnastics. Among boxers we interviewed, those members of the junior and adult national team who won medals at an international championship $(n=15)$, whereas in rhythmic gymnasts we had the opportunity to interview the entire current national team $(n=7)$. Our questions focused on the topics mentioned in the above hypotheses. In the paper, the content of the interviews is analyzed, which included the opinions of the women about themselves and the sport they chose to participate in. In addition to this, we were also interested to find out how sporting females who chose a very feminine sport and women who practice a traditionally masculine sport see one another

\section{Results}

\section{The family as the primary context of sport socialization}

The family, being the primary scene of socialization, influences not only whether the child is going to do sports and, if yes, what kind of sport it will be, but also what kind of sports can be possibly chosen and on what level. The financial situation of the family determines the opportunities to be involved in sport. The children of more affluent and better-qualified parents stand a better chance to become elite athletes as well (Velenczei \& Gál, 2012). The social determinedness of participation in sport can also be seen in the social composition of the junior sporting elite, marked by the sport-related cultural capital of individuals and their value preferences in relation to sport.

Research conducted in recent decades showed that the higher the socioeconomic status of an individual, the more likely he/she is to be connected to higher prestige sports as a supporter or an active participant. For decades, boxing has been a sport whose social base is largely recruited from the lower and lower-middle classes in Hungary. This was also characteristic in the case of the female boxers in our sample, since their majority also came from these strata and only one boxer's family belonged to the upper social strata. It has to be noted here that while among male boxers in Hungary coming from socially disadvantaged families (in many cases of Roma ethnicity) represent a considerable ratio, the same cannot be stated in the case of female boxers. Members of the female national team come from different parts of the country, and according to them, their location has no influence on their membership. Apart from the centrally organized training camps, they only meet at competitions and do not necessarily know each other. 
On the other hand, the families of rhythmic gymnasts can all be characterized by higher status. With no exception they all reside in Budapest. There were some that originally came from the countryside, but because of their sporting career had to move to the capital. Before major competitions, rhythmic gymnast girls spend a daily 10-12 hours in common training, meaning that they practically see their team mates more than their parents. The related costs of the sport are high in comparison with boxing; the dresses and equipment have to be purchased by parents.

Regarding educational level, boxers (average age $=23.73$ years) and rhythmic gymnasts are similar; however, it must be noted that the latter, owing to their young average age (17.71 years) have not yet finished secondary school. Boxers used to be characterized with low educational level; in fact, among males this still holds, but it cannot be said about female boxers. Several members of the national team have secondary qualification or study in higher education. All athletes worked or studied in addition to their sporting career, but among female boxers, some earned their living as professional athletes.

The significance of parental encouragement is also underlined by our research, since the love of sport was present in the families of all the interviewees, almost like a tradition. Indeed, the children of sporting parents are more likely to become competitive athletes, and the sport socialization of girls is typically more successful if their mother was or is physically active (McPherson et al., 1989). According to our results, it was not only the positive attitudes to sport that were 'inherited' by the daughters, but the kind of sport they became engaged in as well.

The mothers of rhythmic gymnasts used to do gymnastics or ballet, whereas with the mothers of female boxers, the team sport considered to be the most masculine; that is, handball was the most prevalent. In the case of rhythmic gymnasts, their sport was selected by the parents, usually by the mothers; however, this is not surprising, since this sport must be started in early childhood in order to reach the international level. Boxing is different in this respect, as it is reached at a later age and typically via other sports by the children. Our respondents can also be characterized by this pattern; they all chose boxing after trying other sports and based on their own decision.

"I have tasted many sports, then I tried boxing and it was love at first sight. I stuck there" (32-year-old boxer).

It may be surprising, but we also met an athlete who used to do RG, but later turned to boxing: "Boxing was not the first sport I had met. My parents took me to rhythmic gymnastics first and then I danced acrobatic rock and roll, but neither of these was the real thing" (25-year-old boxer).

In addition to the specificities of sport selection, the extent of parental encouragement is also very different in the two sports. Since rhythmic gymnastics is selected by the parents for their daughters, their support continues later on as well. We only encountered one exception when the parents worried about the health of their child from the harmful effects of elite sport.

"My parents are not very pleased that I do this sport, but they have to support me now that it went this way, however, they think I will be crippled in the end" (19-year-old rhythmic gymnast).

In the case of the female boxers, it could be observed that not only was the parents' support missing, but nearly each of the parents opposed, or even forbade, their daughters to participate in this sport. As it turned out during the interviews, the main reason for this was that parents wanted to protect their children from the supposed harms of boxing.

"My mother strongly opposed it, as I am her only daughter, and she was afraid that I would get seriously injured" (27-year-old boxer).

"They were really worried that I would be harmed in this sport and they only accepted it when good results came. Later they were happy that I have found what I would like to do" (23-yearold boxer). 
"My mum was afraid, as she said; if I do this sport I will become ugly" (19-year-old boxer).

The reasons for parental opposition also included the lack of acceptance and low prestige of female boxing. In these periods, the persistence of the athletes - and later, their sporting success - was needed to tackle family objections to boxing:

"Both my dad and my mum prohibited boxing, but I was so headstrong that they finally gave in that I could try it. I did and it worked" (27-year-old boxer).

"My parents were very unhappy, and although they did not veto it, they really hoped I would lose interest soon” (22-year-old boxer).

"Mom was not pleased about it, dad simply laughed at me. Then later when they saw that it was serious, they came to accept it somehow" (24-year-old boxer).

"My mother was not happy that I chose such sport, she would have preferred gymnastics, or some team sport. At that time the society judged girls engaging in combat sports in a harsher way" (36-year-old boxer).

Nevertheless, the most articulated example of the conflict between parents and their daughter in connection with sport selection was undoubtedly the case of the athlete who was forced to lie about boxing, as her parents did not let her follow the footsteps of her grandfather, who was an Olympic boxer. Here it was only the success of the athlete, which later helped the parents accept her decision.

\section{The early stage of gender socialization and sport socialization}

In studying gender socialization, we become familiar with the forms of behavior that are acceptable for our gender, the values and norms related to the concepts of masculinity and femininity in the given age and society. This process starts from the moment of birth, whereas sport socialization, that is, the process of familiarizing with sport starts at a later stage of childhood. The two processes have some interconnections as well: sport as a tool for socialization has always played a more important role in socializing boys to become men than in bringing up girls to become women. Therefore, sport has been used as an instrument for creating and developing masculine characteristics and personality traits. The family, the parents are able to influence the gender identity of their child and his/her attitudes to sport. At the same time, parents who insist more strongly on traditional gender roles are more likely to direct their daughter towards sports that are more acceptable for women.

As it has been mentioned in the section discussing the international literature, childhood role behavior and sport selection often correspond. Thus, as a first step we examined whether the female athletes interviewed differed in their childhood activities, and if yes, to what extent. Initially it was expected that female boxers could be characterized by boyish childhood behavior, while rhythmic gymnasts would report on more feminine kinds of activities. However, during the interviews this was not supported by the athletes, as they showed no major differences in this respect. In both groups, girls' and boys' games were both present in their childhood, the latter mainly thanks to a brother.

"In my childhood, I used to play all sorts of things with my brother and sister; it depended on who I was with. I had male and female friends as well" (19-year-old boxer).

"In my childhood I already practiced in my room, I did not play with dolls, since I have a brother, I rather played boyish games" (20-year-old rhythmic gymnast).

We did not find real tomboys among boxers, either; just as with the rhythmic gymnasts, they also recalled a colorful childhood game-structure. The way they spent their leisure time was considerably affected by whether they had brothers or sisters. 


\section{Female athletes in traditional gender roles}

In connection with gender roles, we were mainly interested in exploring how many of the female athletes adhere to patriarchal traditions or how much they reject them. Since in Hungary, gender inequality is mainly manifested in the time spent with housework, in our research we asked the representatives of both sports about their views on how much housework should be regarded as female activity, and in what proportion they share or would share household duties with their male partners. As rhythmic gymnasts are very young, they generally do not maintain an own household, so we also asked them how much they consider the division of labor they saw at home between their parents an example to be followed. As it was revealed by their answers, the majority of their parents follow the traditional gender roles, so most of the housework is done by the woman. The athletes interviewed agree with this and see it as an example to follow, and although they do not have their own household, they would even find a 90-10\% ratio acceptable.

"Well, this is what society expects of women" (24-year-old boxer).

"My mother would not even let my father into the kitchen, but I think that's no problem" (17year-old rhythmic gymnast).

Female boxers had similar remarks, and their opinions were also influenced by the fact that in many cases they already maintained their own households. They also think that housework is mainly a female duty, and only share it with their partners because besides work and sport they have less time to do it. This becomes especially important if both of them are elite athletes.

"In our place everyone helps with the housework. Regardless of this, I think it is 100\% female duty” (18-year-old rhythmic gymnast).

"It is mostly the woman who cooks, washes, cleans the house, but it is better if divided. Whoever has more time, but I think it is 70\% female, 30\% male activity" (28-year-old boxer).

In the opinions about gender roles, the kind of sport was therefore not reflected; what could rather be observed were the traditionally patriarchal views of Hungarian women.

\section{Female athletes about their own sport and themselves}

In Hungary, the popularity of rhythmic gymnastics and boxing is fairly low, thus people less interested in sport in general do not know much about these two sports. Their audience is recruited from sport professionals, and the relatives of the competitors. The extent of their media representation is negligible; in recent years, due to a lack of Hungarian participants, they are barely covered, even during the Olympics. In connection with professional fights, it is only men's boxing which appears in the printed and electronic media. Due to the superficial knowledge of the sports, only stereotypes exist related to rhythmic gymnastics and boxing, especially to its female segment, which describe the two fundamentally different sports and their representatives with opposite characteristics. According to these, RG and the women participating in the sport are the embodiment of femininity, while the sport of boxing and boxing women represent masculinity in sport. Thus, it was an especially interesting question how the athletes themselves describe their own sport, since it could be assumed that their views would diverge from those prevailing in society. In the case of the representatives of both sports, we experienced that they emphasized the positives in connection with their own sport, but they were also aware of its specificities that could be perceived as negative. Female boxers regard their sport to be skillful but masculine, demanding endurance, willpower, and hard work. They do not see it as rougher than other combat sports; what is more, in their opinion, the risk of injury is even lower, because during training and matches body protectors are used. They are aware of the fact that they do a sport that is masculine and socially less acceptable for women, but they think that the characteristics necessary for success, such as firmness and the ability to struggle make them more self-confident, which helps them achieve their goals in civil life as well. As it was remarked by our boxing interviewees with almost no exception:

"The outside world is still surprised when they hear that a girl chose boxing to be her sport". 
They agree that compared to other sports, in boxing there are more girls who look boyish, and who, in addition to their appearance, took up some other masculine qualities (the way they walk, talk, and behave); however, the majority of the boxers distance themselves from this. They try to remain as feminine and as sporty in their everyday lives as any other ordinary woman would do.

The rhythmic gymnasts interviewed are proud that their sport is indeed the most feminine of all, and they do not see it as a positive tendency that nowadays it is done by men as well. In their opinion, it is funny rather than aesthetic. Nevertheless, they unanimously think that in order to achieve good results in their sport they need to train dauntlessly and in an above-average training time. This requires extraordinary endurance, as mentioned by a 19-year-old rhythmic gymnast:

"I think it is a really feminine and spectacular sport, but at the same time it requires hard work and tenacity".

Gymnast girls "wear" their femininity in civil life as well; their slim figure, body posture, and hairstyle reveal their sport. Their attractive, feminine appearance and their inner characteristics necessary for sporting success, which can be considered as masculine, show some sort of ambivalence.

Let us see how the athletes interviewed see each other and each other's sport.

\section{Boxers on RG and rhythmic gymnasts}

Not every female boxer interviewed was familiar with rhythmic gymnastics; they generally had little insight about the sport. Those who had some information regarded RG to be beautiful, spectacular, and very feminine. They see this sport as art at the same time:

"They do incredible things with their body, it is wonderful and I can see the huge amount of work in it as well".

There was only one female boxer who, as opposed to her colleagues, does not recognize the values of rhythmic gymnastics.

"Throwing clubs and waving ribbons. It doesn't seem to be a serious sport. I never watch it. It doesn't interest me, although I have seen it before. It cannot be compared to gymnastics, which is much more serious".

Representatives of RG are regarded to be pretty and feminine. On the other hand, they also voiced some concerns about the sport:

"They are slim. They are anorexic. One cannot be thin enough to do this sport, it is not particularly healthy".

"I think this sport is done at a competitive level by girls until they are 18-20. It is typical that they delay maturity by nutrition and asceticism".

The majority of boxers think that the femininity represented by this sport cannot be accepted as "healthy". Interestingly, as it is mentioned above, in connection with their own sport, which is regarded by the society as more dangerous and harmful to health, they did not express similar concerns.

\section{Rhythmic gymnasts on female boxers}

Women engaged in RG had much stronger views related to boxing and the involvement of females in the sport. They do not like to watch boxing, not even if men fight in the ring, and they have not even seen women boxing only when hitting punching bags in the fitness gym. As they see it, female boxers are very different from them.

"These women are tougher and more aggressive, and then their sport also socializes them this way; they can gratify their aggressive tendencies". 
They almost unanimously reject female boxing; only one respondent showed sympathy for masculine sports, particularly boxing:

"I really like this sport; my grandfather was a boxer and I also watch it. He has told me a lot about it and I liked it a lot, maybe it is even harder than RG. I think it is just great that there is female boxing”.

The majority of the rhythmic gymnasts do not find an acceptable explanation to why a woman would choose boxing, which makes them masculine in terms of both inner and outer characteristics. The only positive they see is that with the help of their boxing competencies, they can protect themselves in civil life.

"I think female boxing is horrible. It is not a feminine thing".

"Women who do a masculine sport probably grew up as tomboys and saw this in their environment, so they have boyish tendencies"

Rhythmic gymnasts do not understand it either, how parents can allow their children to be engaged in boxing. Even so, they would not support their son participating in RG. They claimed that RG should be preserved as an exclusively female sport, because the inclusion of men would ruin the prestige of the sport.

\section{Conclusion}

The tendency that sports that used to be traditionally masculine or feminine have become "unisex" raises the question of whether stereotypes related to these sports and their representatives will change in the future. In our research, we dealt with two sports, which, due to being single-sex earlier, could clearly be characterized by stereotypes related to masculinity and femininity. Nevertheless, today in boxing, the sport considered as the most masculine, women also compete, whereas in the most feminine sport, men have appeared. The question can be raised whether in the future a single-sex version of these sports is to evolve, or the gender identity of the athletes participating in the sports is going to remain questioned.

When examining the latter aspect, it might be worth analyzing the questions our study has been dealing with: the process of sport socialization, the circumstances of sport selection, and the views in relation to traditional gender roles. In terms of their childhood activity structure, female boxers and rhythmic gymnasts were no different from each other; therefore our assumption according to which women engaging in masculine sports used to do boyish activities already in the early stages of their life has not been verified. In this respect, the presence or absence of brother(s) was more decisive among boxers and rhythmic gymnasts alike. On the other hand, when examining the process of sport selection we encountered significant differences. RG is a sport selected typically at an early age by the parents, mainly by the mother who used to do some sort of feminine sport, while boxing is selected by the female athletes at a later age, based on their own decision and often against the will of parents. Accordingly, in the case of the latter, the support of the family cannot be observed as much.

Contrary to our previous expectations we did not experience that the representatives of the two sports show differences in their views about traditional gender roles. Female boxers and rhythmic gymnasts regard the patriarchal distribution of roles characteristic of their families as an example to be followed, which can mainly be marked by the disproportionate weight of housework in the activity structure of women.

Similar to the tendencies described in Matteo's study (1986), according to which when sex-typed females were compared with androgynous and cross-sex-typed females, they reported significantly less commitment to masculine sports, we also observed in our research that the opinions of the representatives of the feminine sport ore strongly stereotypical, at times even extreme, as opposed to the views of female boxers in connection with rhythmic gymnastics. 


\section{REFERENCES}

Chimot, C., Louveau, C. (2010). Becoming a man while playing a female sport: the construction of masculine identity in boys doing rhythmic gymnastics. International Review for the Sociology of Sport, 45(4), 436-456.

Davisse, A., Louveau, C. (1998). Sports, école, société: la différence des sexses. Féminin, masculin et activités sportives /Sport, school, society: the gender difference. Female and mal sport activities/. Paris: L'Harmattan.

Guttmann, A. (1991). Women's Sports: A History. New York: Columbia University Press.

Hadas, M. (2003). The Birth of the Modern Man. Helikon Kiadó: Budapest.

Halbert, C. (1997). Tough Enough and Woman Enough: Stereotypes, Discrimination and Impression Management Among Women Professional Boxers. Journal of Sport and Social Issues, 21, 7-37.

Hasbrook, C. (1993). 'Gendering Practices and First Graders' Bodies: Physicality, Sexuality and Bodily Adornment in a Minority Inner City School. Paper presented at the North American Society for the Sociological Study of Sport Annual Conference. Ottawa, 6-10. November.

Hills, L.A. (2006). 'Playing the field(s): an exploration of change, conformity and conflict in girls' understandings of gendered physicality in physical education'. Gender and Education, 18(5), 539-556.

Kamberidou, I. (2007). The Social Gender and Sport Identity: a Bio-socio-cultural Interpretation. In B. Kratzmuller, M. Marschik, R. Mullner, H. Szemethy, E. Trinkl (Eds.), Sport and the Construction of Identities (pp. 584-501). Vienna: Verlag Turia \& Kant.

Kemberidou, I., Tsopani, D., Dallas, G., Patsantaras, N. (2009). A Question of Identity and Equality in Sports: Men's Participation in Men's Rhythmic Gymnastics. In M. Arnot, M. Mac an Ghaill (Eds.) The Routledge Falmer Reader in Gender and Education (pp. 220-237). New York: Routledge.

Kirk, D. (2002). Physical Education: a gendered history. In D. Penney (Ed.), Gender and Physical Education, Contemporary Issues and Future Directions (pp. 24-37). New York: Routledge.

McCaughey, M. (1997). Real Knockouts: The Physical Feminism of Women's Self-Defense. Albany: New York University Press.

McPherson, B., James, C. Loy, J. (1989). The Social Significance of Sport: An Introduction to the Sociology of Sport. Champaign, IL: Human Kinetics Press.

Mennesson, C. (2000). 'Hard' Women and 'Soft' Women: The Social Construction of Identities among Female Boxers. International Review for the Sociology of Sport, 35(1) 21-33.

Messner, M.A. (1996). Studying up on Sex. Sociology of Sport Journal, 13, 221-237.

Metheny, E. (1965): A collection of speeches about sport and dance as significant forms of human behavior. Dubuque, Iowa: W. C. Brown Co.

Pirinen, R. (1997). Catching up with men? Finnish newspaper coverage of women's entry into traditionally male sports. International Review for the Sociology of Sport, 32, 239-249.

Pfister, G. (1990). The Medical Discourse on Female Physical Culture in Germany in the $19^{\text {th }}$ and Early $20^{\text {th }}$ Centuries. Journal of Sport History, 17, 183-199.

Postow, B.C. (1980). Women and masculine sports. Journal of the Philosophy of Sport, VII, 51-58.

Sandow, E. (Ed.) (1898). Physical Culture. London: Gale \& Polden LTD.

Scraton, S., Fasting, K., Pfister, G., Bunuel, A. (1999). It's Still a Man's Game? The Experiences of Top-Level European Women Footballers. International Review for the Sociology of Sport, 34, 99-111.

Snyder, E.E., Spreitzer, E. (1973). Family influence and involvement in sports. Research Quarterly, 44, $249-255$.

Thing, L.F. (2001). The Female Warrior. Meanings of Play-Aggressive Emotions in Sport. International Review for the Sociology of Sport, 36, 275-288.

Velenczei, A., Gál, A. (2011). New Challenges, Old Answers in Hungarian Sport: The Case of Talent Management. European Journal for Sport and Society, 8(4), 281-297.

Walton, T. (2005). Pinned by Gender Construction?: Media Representations of Girls' Wrestling. Women in Sport and Physical Activity Journal, 14(2), 52-68.

Watson, G.G. (1975). Sex role socialization and the competitive process in Little Athletics. Australian Journal of Health, Physical Education and Recreation, 70, 10-21.

Webster, F.A.M. (1930). Athletics of To-day for Women: History, Development and Training. London and New York: Frederick Warne \& Co., Ltd.

\section{AUTHOR'S ADDRESS: $\quad$ Andrea Gál}

Buday László u. 8/a

1024. Budapest, Hungary

Email: gala@mail.hupe.hu 